\title{
Metal en la aldea: La construcción de una escena musical urbana en Costa Rica (1980-1992)
}

Recibido: 7 de septiembre 2020 Revisado: 24 de mayo 2021 Aprobado: 5 de julio 2021

Sergio Isaac Hernández Parra Costarricense. Historiador y estudiante de Filología Española en la Universidad de Costa Rica.

Investigador independiente. Sus líneas de investigación versan sobre la música popular en la historia reciente de Costa Rica y la regulación cultural durante el mismo periodo. Correo electrónico: sergioherpar@gmail.com

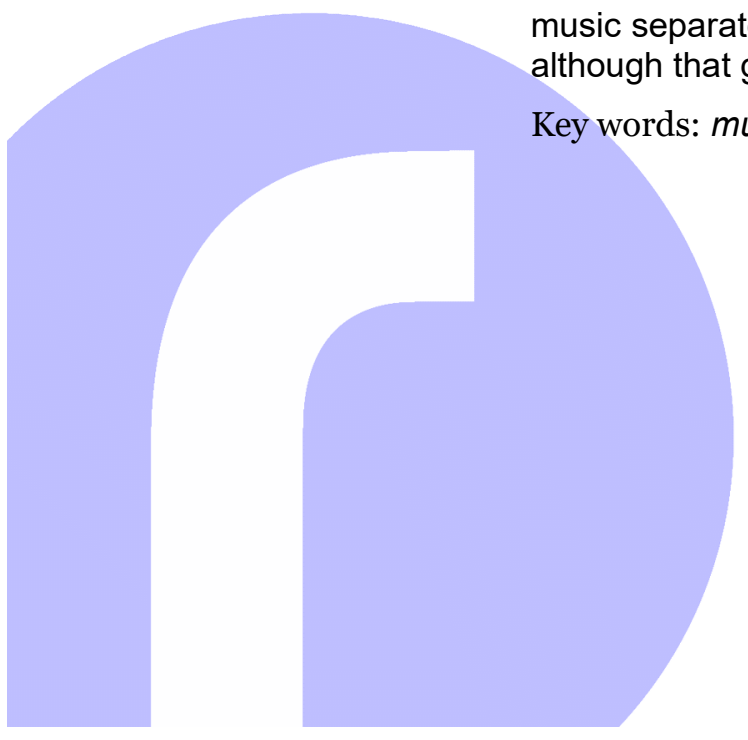

Resumen: Las escenas musicales dinamizaron el paisaje cultural costarricense a finales del siglo XX. Estas formaciones se originaron gracias al auge de las juventudes, el consumo cultural y los procesos de urbanización. Además, fueron lideradas, en primera instancia, por las prácticas musicales del rock y el metal. De acuerdo con esta premisa, la presente investigación se planteó como objetivo analizar la construcción de la escena musical metal en Costa Rica entre los años 1980-1992. Con este fin, el trabajo abordará las dinámicas musicales y culturales que permitieron al metal conformarse como escena, y que conllevó a una creciente estigmatización social.

Palabras clave: escena musical, prácticas musicales, música rock, música metal

\section{Metal Music in the Village: The Making of an Urban Music Scene in Costa Rica (1980-1992)}

Abstract: Music scenes were the most influential expressions in Costa Rican popular culture at the end of the twentieth century. These cultural formations were facilitated by the public relevance of the youths, and the growth of cultural consumption and urban areas. Also, they were leaded by the rock and metal music; therefore, the purpose of this paper is to analyze the articulation and evolution of the metal urban scene of Costa Rica between the years 1980-1992. For that, this investigation will provide evidence of how the metal music separate himself from the rock music and set his own musical dynamic, although that generated public awareness.

Key words: music scene, rock music, metal music, music practice 
1. El pánico moral es un periodo de alta ansiedad moral que permite a ciertos sectores, principalmente conservadores, delimitar los límites de lo permitido y de lo moralmente aceptable. En el caso de 1992, se tuvo como objeto de ansiedad social a la juventud metalera, la cual fue perseguida y estigmatizada. Por consiguiente, la escena metal fue desestructurada y sus prácticas estéticas y musicales se percibieron como perjudiciales. Hernández Parra Sergio Isaac. Jóvenes, 'rock satánico' y el pánico moral de 1992 en Costa Rica. Tesis de Licenciatura en Historia, Universidad de Costa Rica, 2016.

\section{Introducción}

A mediados del siglo XX, la música popular en Costa Rica recibe el influjo del rock que, rápidamente, ganó adeptos. La formación de bandas, espacios de interpretación musical y aficionados fieles creó una escena que evolucionó junto con las nuevas sonoridades roqueras. De ahí que, en la década de 1980, surgiera la escena metal en el Valle Central. Esta formación cultural, que se rige por prácticas musicales, es el tema del presente trabajo, en el cual se interroga sobre los factores sociales y culturales que permitieron el surgimiento de las expresiones musicales metal. En consecuencia, se plantea como objetivo analizar la construcción de la escena musical metal en Costa Rica.

En esta investigación, se pretende profundizar la reflexión que Hernández Parra introdujo en la tesis de licenciatura en Historia Jóvenes, 'rock' satánico y el pánico moral de 1992 en Costa Rica (Hernández Parra 2016) sobre la conformación de la escena metal, mas no se desarrolló rigurosamente, ya que sobrepasaba los límites de esa investigación. En consecuencia, esa discusión se retoma en este artículo y se plantea como una investigación independiente y complementaria.

Para ello, se aplicó una metodología que se apega a la reconstrucción histórica de las prácticas musicales del rock y el metal. Así, gracias a una búsqueda sistemática en fuentes de hemeroteca, principalmente en el diario $\mathrm{La} \mathrm{Na-}$ ción, y los semanarios Eco Católico y Semanario Universidad, que abarcó la década de 1980, se detectaron los espacios de interacción musical, la formación de bandas y la producción de conciertos. Además, esas fuentes se triangularon con los discursos de los músicos y otros sujetos involucrados en prácticas musicales que recopilaron Priscila Carballo (2017) y Rafael Corrales Ulate (2011).

Por otra parte, la investigación fijó sus límites temporales entre los años de 1980 y 1992. La década central es la de los ochenta porque fue el periodo en que se definió la dinámica musical, aunque es necesario exponer los antecedentes de las décadas de 1960 y 1970. Por otra parte, el año de 1992 es la fecha cuando se desarrolló el pánico moral ${ }^{1}$ que puso fin a la evolución de la escena metal, la cual debió reconfigurarse años después. De acuerdo con este marco temporal, el trabajo se estructura así: primero, se identifican las expresiones musicales y culturales que dan inicio al rock y su vertiente pesada en el país; segundo, se determinan las dinámicas que dotan a la escena metal de autonomía; tercero, se examina la consolidación de las prácticas musicales metal y su proceso de marginalización social.

En el presente trabajo, se utiliza el concepto "escena" como término explicativo para el análisis social de la música (Bennett 2004, 223). De acuerdo con este, las prácticas musicales forman una unidad cultural (Sans 2016, 38), la 
cual involucra a una red de individuos que interactúan en un campo considerado propio (Mendívil y Spencer 2016, 7). La escena, entonces, no representa un colectivo o una comunidad, pues no es un objeto, sino una relación social generada por la práctica musical. Por otro lado, la escena puede ser subordinada y convertida en objeto de control social (Mendívil y Spencer 2016, $161)$; en ese caso, es vigilada y morigerada. Esto, como se verá en las secciones siguientes, es patente en la escena metal costarricense. Lo anterior implica entender la escena como un espacio en disputa por parte de los proyectos culturales, incluso los dominantes.

La escena permite ir más allá de las culturas juveniles porque es dinámica, $y$, más que una afinidad etaria - la cual es significativa, principalmente en el aspecto de generación-, revela una adscripción en términos de estilos de vida, en particular en América Latina (Mendívil y Spencer 2016, 7). Sin embargo, las reflexiones sobre las culturas juveniles (Feixa 1998, 84-105) mantienen su pertinencia en el análisis de las escenas musicales, ya que los elementos estructurales (generación, género, clase, etnicidad y territorio) están presentes. Sin embargo, la escena atraviesa estas estructuras, y no es delimitada por ellas (Lancina 2017, 39).

En suma, el concepto de escena posibilita rastrear, explicar y exponer la formación cultural que las prácticas musicales metal dieron origen, principalmente, gracias a que la escena permite examinar las rupturas y discontinuidades de las prácticas musicales (Mendívil y Spencer 2016, 2). Es decir, la escena es un proceso, de ahí que sea un concepto adecuado para el análisis histórico de la música. Esto se considera relevante, pues el metal fue uno de los primeros géneros que adquirió autonomía escénica, lo que lo convierte en el germen cultural que facultó la construcción de escenas musicales populares y urbanas en la década de 1990.

Por consiguiente, la dinámica de la música popular de finales del siglo $X X$ e inicios del XXI no puede comprenderse sin el análisis de la construcción de la escena metal en la década de 1980, la cual, a su vez, fue objeto de vigilancia y control social. Esto indica que las prácticas musicales son vistas con recelo por los procesos culturales hegemónicos de final de siglo XX. Por lo tanto, analizar las escenas musicales no solo implica dar cuenta de formaciones socioculturales específicas, sino que brindan luz para el análisis social e histórico de periodos concretos. Esto se estudia a continuación.

\section{Orígenes y expansión del rock}

En Costa Rica, antes de la década de 1950, la música rock no formaba parte del repertorio de música popular que Juan José Marín denominó melodías de perversión (Marín, 2009). De ahí que interrogarse sobre las primeras manifestaciones musicales y culturales del rock y el metal en Costa Rica es relevante en este primer apartado; por consiguiente, se identificarán estas primeras expresiones vinculadas con el rock y el metal de la siguiente forma: primero, se da cuenta del desarrollo del rock como género musical; segundo, se 
presentan las primeras formaciones musicales costarricenses de rock; tercero, se describe la situación del rock que permite entender el desarrollo del metal en la década de 1980.

La tradición que da origen al rock se remonta a las expresiones musicales afroamericanas de los esclavos, en el sur estadounidense, las cuales conforman, en los siglos XIX e inicios del siglo XX, el blues y el rhythm and blues. Estas prácticas musicales, de igual forma, tomaron el tren subterráneo (metáfora sobre las rutas que utilizaron los esclavos del sur para dirigirse al norte no esclavista) y se establecieron en Chicago (Bennett 2001, 12). Así, hacia mediados del siglo XX, el rock fue "blanqueado" con el objetivo de que lo aceptara el público norteamericano: Elvis Presley imitó a los músicos afroamericanos Fats Domino y los Drifters al mostrar la rudeza, la energía y la sexualidad que estos transmitían. Por consiguiente, la popularidad creciente del rock ' $n$ ' roll fue canalizada por la industria musical y el floreciente capitalismo estadounidense. La música popular, entonces, fue un objeto de consumo, principalmente juvenil (Passerini 1996, 381-453).

En la década de 1960, el rock incorporó elementos de la música folk estadounidense y dio mayor énfasis instrumental a la guitarra y la batería (Corrales Ulate 2011, 42). Por su parte, el metal se consolida, entre 1968 y 1972, cuando surgen los estilos art rock, southern rock, songwriter y heavy metal. De igual manera, en este periodo se forman las actitudes, particularmente hippies, que serán características del heavy metal, tal como el uso del blue jeans, el pelo largo, el consumo de drogas, la apertura sexual, la desconfianza hacia la autoridad y la percepción del artista de rock como esencia moral (Corrales Ulate 2011, 45). En las décadas siguientes, el metal adquiere mayor popularidad con las bandas inglesas Led Zeppelin y Black Sabbath (Corrales Ulate 2011, 46).

En Costa Rica, en una etapa de expansión urbana y de formación de la clase media, se observa que el rock se inserta dentro de una dinámica cultural dirigida por tres corrientes (Mondol 2015, 161-168): 1) la formación de una cultura nacional construida por el proyecto institucional del Partido Liberación $\mathrm{Na}$ cional, y, principalmente, por los proyectos artísticos promovidos por el recién creado Ministerio de Cultura, Juventud y Deportes; 2) la corriente con un contenido político-ideológico propia de circuitos intelectuales y estudiantiles que simpatizan con la izquierda latinoamericana, y 3) el impacto de la industria cultural (estadounidense y latinoamericana) que origina la cultura de consumo gracias a la radio, los discos gramofónicos, el cine y el auge de la televisión. El rock debería entenderse por la tercera corriente.

Al igual que en ciertas localidades latinoamericanas (Cousinet et al. 2009, 3740 ), en Costa Rica, la escena del rock se inicia a finales de la década de 1950. Empero, existe una polémica por determinar quiénes fueron los y las precursoras. Raúl Saavedra, locutor radial, afirma que la primera agrupación fue Walter Chacón y las Twist Masters (Minsky 1991) —no queda claro si las Twist Masters eran acompañantes femeninas, lo que demostraría una participación muy temprana de mujeres-. No obstante, Leonel Alfaro, fundador de 
Los Thunder Boys, asegura que ellos fueron los pioneros, ya que se formaron en 1962 (Minsky 1991). Por su parte, la investigadora Priscilla Carballo documenta que, en el año 1958, el grupo de rock ' $n$ ' roll Los Perros Calientes (conformado por estudiantes universitarios) se presentó en los cines Isabel y Daisy, ubicados en Heredia y Paso Ancho, respectivamente (Carballo 2017, 46). En cualquier caso, "la época de oro del rock nacional" se vivió entre los años 1967-1970, según lo señala el periodista Tony Montes del Eco Católico (Montes 1982).

Este florecer roquero se debió, tal como lo menciona el músico y compositor nacional Carlos Guzmán, a que el éxito comercial de las bandas internacionales impactó la estética y el gusto musical de la juventud costarricense (Mondol 2015, 166), lo que motivó la conformación de grupos como: Los Rufos, Los Gatos, Los Thunder Boy's, Los Vikingos, Apple Band, Scorpions, Spiders, Play Mates, Los Rockets, los Pockers, Los Blue Jets y The King Cats. La mayoría de estos grupos tocaba versiones en español de los éxitos internacionales (Mata 1989). Esto corrobora el impacto que provocó la industria cultural estadounidense en el imaginario y formación de bandas.

Un aspecto importante de este periodo fueron los espacios en donde se interpretaba el rock: los cines (Carballo 2017, 83-85). Estos locales de entretenimiento surgieron a inicios del siglo $\mathrm{XX}$ y rápidamente se instalaron en comunidades y barrios. En consecuencia, se constituyeron en centros de ocio y entretenimiento, particularmente para los sectores populares (Acuña et al. 1996, 93) —se recalca que el Teatro Nacional, para esta época, era el estandarte de la cultura burguesa-. Debido a la existencia de esta infraestructura para las presentaciones escénicas y su consolidación como punto de consumo cultural y de encuentro social, no es de extrañar que fuera aprovechada por los y las roqueras. Esto indica que el rock, en tanto práctica musical, se ubica dentro de las expresiones populares.

La importancia del cine no descansa solamente en la presentación en vivo de las bandas costarricenses, sino que era un medio en donde se mostraban las tendencias juveniles de la época, de manera que impactaba en el consumo y la estética juvenil. Se constata, gracias al reportaje de Luis Fernando Mata, "Woodstock veinte años después", publicado el 14 de agosto de 1989 en La Nación, que un documental con escenas del festival estadounidense Woodstock fue transmitido en el año 1969, lo que ayudó a consolidar el uso del pelo largo, los pantalones campana y a propagar los símbolos de "paz y amor". Estética de influencia hippie que fue víctima de represión (Sequeira 2020, 1011).

La música igualmente circuló, ya que se vendió el disco que contenía "lo mejor" del festival de Woodstock. Rafa Rojas (citado por Mata), ejecutivo de la empresa discográfica INDICA, afirmó: "yo personalmente vendí los discos en las afueras del cine Rex, donde se estrenó el documental sobre Woodstock; las ventas fueron un éxito". Por otra parte, el reportaje de Mata señala que el impacto de Woodstock se observa, asimismo, en las nuevas agrupaciones, las cuales, por la influencia de Carlos Santana, añadieron sonidos sincopa- 
dos latinoamericanos; esto es patente en las agrupaciones Bocaracá, Sección de Paz y Modulación.

En las siguientes décadas, el papel de los cines se debilitó por la expansión urbana. El historiador Iván Molina demuestra que, entre 1960 y 1980 (proceso que se intensifica en la década de 1990), el crecimiento conurbano debilitó las identidades locales -en las cuales los cines tenían un papel especialen favor del consumo masivo que se lleva a cabo en los centros comerciales de las afueras de la ciudad (Molina 2010, 83-92). Así pues, al decaer el papel de los cines, el rock debió buscar nuevos espacios y, puesto que en esta etapa su aceptación no fue masiva, su consumo se desarrolló fuera de los centros comerciales; de ahí que, contrario a lo mencionado por Molina, el local del que se apropiaron los y las jóvenes roqueras no fue la discoteca, sino el bar. Aunado a este desplazamiento de la escena y de la decadencia de los centros urbanos, el sonido del rock adquiere un matiz pesado que se acerca al heavy metal.

Un bar icónico a finales de la década de 1970 e inicios de 1980 fue Génesis (Tovar 1979). El local, que estuvo ubicado 400 metros al norte del cruce entre Colima y Llorente de Tibás, fue inaugurado en diciembre de 1978 por tres jóvenes, uno de ellos, Johnny Schroeder, fue parte del grupo Hebra -creado en 1979 con el fin de componer música original (Carballo 2017, 53) - en su primera formación. Esta taberna "rock" fue un espacio central en la escena rock del periodo, no solo por la música, sino por difundir este género como cultura; de ahí que fuera considerada por el baterista del grupo Hebra, Carlos Meléndez, como un templo (Carballo 2017, 83-85). A este respecto, los dueños del local expresaron:

$$
\begin{aligned}
& \text { empezamos con música, pero muy pronto haremos la pri- } \\
& \text { mera exposición de fotografías y pintura 'rock'. También, } \\
& \text { para dentro de algunos meses, se montará la primera } \\
& \text { obra de teatro en esa modalidad, en lo cual ya está traba- } \\
& \text { jando un grupo de artistas (Tovar 1979). }
\end{aligned}
$$

Enrique Tovar, periodista de La Nación, en el artículo "Génesis: primer centro de cultura 'rock'", publicado el 2 de marzo de 1979, escribe que "los fines de semana, Génesis se transforma en un festival. Son tantos los jóvenes que llegan al lugar, que muchos se quedan puertas afuera". No obstante, el autor aclara que adultos de más de 40 años, quienes vivieron la primera ola del rock ' $n$ ' roll, asistían al local de manera regular. Esto confirma que la escena del rock tenía un carácter juvenil, pero no se definía por la estructura etaria. Por otra parte, los jóvenes dueños de Génesis (citados por Tovar) dan cuenta del carácter alternativo de la escena:

Queremos que se aprecie más la expresión 'rock' en nuestro país. Es una manifestación propia de nuestra 
época, que arrancó con la música pero que ha invadido otros campos del arte. Es de lamentar que las discotecas locales no hayan querido ver la importancia de este tipo de música.

Génesis fue, igualmente, un escenario donde las bandas precursoras del metal, junto con agrupaciones de rock pesado, dieron sus primeros pasos. Hebra, Silla Eléctrica, Distorsión o Crisálida se presentaban en esta taberna rock. Se constata que estos grupos estaban conformados por jóvenes que rondaban la mayoría de edad. Por otra parte, el reportaje de Enrique Tovar deja ver la manera como circulaba la música al señalar que los dirigentes de Génesis recurrieron a personas que coleccionan discos con el fin de poder sonar rock en el local; de igual forma, recibieron la colaboración del programador Tony Barquero de Radio Nacional y de la emisora Top 12, esta última transmitía rock en directo desde Hollywood. Lo que evidencia que este, y posiblemente el metal, se consumía gracias a los discos y la radio.

Con respecto al consumo musical, en octubre de 1980, se evidencia que el rock y el heavy metal circulaban en el país. En este año, el sello discográfico Dideca (Discos de centroamericanos, cuya sede estuvo en Guatemala) comercializó los discos de los grupos internacionales de mayor renombre y publicó la compilación de éxitos del rock "Larga vida al rock" (Montes 1980), con la intención de que las radios reprodujeran esta música. También, Black Sabbath, con la característica "mucho rock pesado" (Fallas 1980), fue promocionado junto con su álbum de larga duración "Heaven and hell". Esta promoción permite no solo demostrar que el metal fue parte del paisaje musical de finales de la década de 1970 e inicios de la década de 1980, sino que compartió la escena con el rock. Este aspecto se demuestra en el bar Génesis, y, como se comprobará en el próximo apartado, fue una constante hasta finales de la década de 1980.

\section{La estridencia de la guitarra}

Durante la década de 1980, la escena costarricense del rock y el metal se especializa musicalmente: el rock crece hacia el rock en español, y el metal se diversifica hacia nuevas sonoridades pesadas. Dicho esto, es preciso interrogarse sobre cuál es la relación entre el rock y el metal; de ahí que el presente apartado examine la dinámica que facilita la autonomía a la escena metal con el fin de encontrar los procesos compartidos entre ambos géneros y aquellos en los que difieren. Con el objetivo de explicar este vínculo, la presente sección se distribuye de la siguiente manera: en una primera instancia, se analizan las transformaciones socioculturales que permiten el desarrollo de la escena rock y metal; en un segundo momento, se presentan las expresiones del rock durante la primera mitad de la década de 1980; y, finalmente, se muestra la tendencia hacia la masificación del rock y el metal. 
2. Acero, integrada en parte por Jorge Molina y Francisco Pujols, es considerada la banda decana del metal costarricense. Estuvo inactiva entre los años 1991 y 1996, y a inicios del siglo XXI dieron su gran salto promocional al llevar la gira de su álbum debut por Centroamérica, y lograr reconocimientos en revistas de importancia internacional. Mora, Víctor, Enciclopedia del Metal

Costarricense (y otras influencias), (San José, Costa Rica,

Subterranean Gremio de Escritores 2011, 3-4).
Hacia la década de 1980, se experimentaron dos procesos determinantes para la conformación de la escena rock en Costa Rica: el auge de la juventud y el consumo cultural de masas. Con respecto a los jóvenes, se constata que la transformación demográfica los catapultó como actores sociales. La población juvenil mantuvo, entre los años de 1960 y 1980, una tasa de crecimiento anual del 4.4 por ciento, encima de la tasa general del 2.9 por ciento (Torres $1987,16)$. Esto dio como resultado que, para el año 1984, un tercio de la población costarricense fuera joven (Kauskopf y Gutiérrez 1990, 1). Por consiguiente, atrajeron la mirada institucional; de ahí que, como lo plantea el historiador David Díaz, los jóvenes, que luchaban por sobrellevar la crisis económica de 1982 y por mejorar su situación laboral y educativa, fueran objeto de un proceso político planificado que buscaba desradicalizarlos y convertirlos en agentes del Estado para defender la situación social conservadora (Díaz Arias 2018, 152-153).

En cuanto al consumo cultural de masa, su implementación se aceleró por el denominado modelo neoliberal, el cual se instauró paulatinamente durante la década de 1980. Bajo este modelo, el país se abrió a la cultura globalizada, la cual erigió al centro comercial como espacio de realización cultural. Lo anterior promovió las identidades de clase que acrecentaron las diferencias socioeconómicas (Molina 2010, 121-128). Por añadidura, si bien la música popular nunca fue objeto de promoción estatal, ahora con las políticas neoliberales fue relegada, junto con la mayoría de las actividades culturales, al ámbito privado (Cuevas Molina 2013, 129).

Lo anterior se comprueba el 1 de agosto de 1982, ya que, como se demuestra en el reportaje de La Nación, "La moda punk, violencia en el vestir y en otras cosas", escrito por Lidiette Brenes de Charpentier, la juventud es vista como un problema por controlar: "las protestas juveniles se han presentado siempre como si fueran el sarampión del género humano: ataca a cierta edad, causa calenturas y malestar, alarma a los demás, pero inmuniza a las personas para el resto de su vida".

Esta preocupación por los y las jóvenes se generó gracias a una actividad punk que se organizó en el Costa Rica Country Club el día 24 de julio, evento que congregó a unos tres mil participantes. Además, Brenes de Charpentier se congratuló de que solamente unos cuantos acogieran la estética punk. No obstante, esta nota es relevante no solo para documentar la presencia de la música punk, que fue el origen de uno de los principales grupos de metal costarricense de la década, Acero $^{2}$, sino porque revela el carácter de clase de esta actividad, ya que se realizó en un club privado.

La escena rock y sus agrupaciones, desde el año 1979, han organizado festivales. En ese año se realizó, en el Monte de la Cruz (Heredia), el "festival de verano del 79" que duró tres días (Carballo 2017, 87). En setiembre de 1982, se celebró un festival rock de tres días en el Teatro Carpa, en donde participó Hebra, Igni Ferroque, Micro Wave, Ciclos de rock y Eterno presente. Uno de los objetivos de estos festivales fue afianzar la escena y la calidad musical, puesto que "la intención de la actividad es crear un público permanente para 
este tipo de música y fomentar la creatividad entre las agrupaciones que la interpretan para que compongan sus propias obras, con el objetivo de consolidar un movimiento "rock" en Costa Rica" (La Nación 1982). Al año siguiente, en 1983, se realizó el "Festival del sol" en La Guácima, que, de igual forma, duró tres días; además, contó con dos tarimas, venta de artesanías y una organización de transporte (Carballo 2017, 87).

Por su parte, la escena metal, hacia la segunda mitad de la década de 1980, señala Paul Vega, seguidor y programador del espacio Rock Sin Fronteras de Radio U —inaugurado en octubre de 1990 (Semanario Universidad 1990) -, consistía en un grupo de amigos: "En Costa Rica no había escena metal, porque éramos simplemente amigos que compartíamos eso" (Corrales Ulate 2011, 57). Asimismo, agrega: "Los grupos de metal en momentos determinados como ese aprovechaban ciertas amistades con otros grupos con los que habían tocado porque prácticamente todos eran una misma camada, los músicos andaban en una edad similar; un contingente que venían del colegio Castella" (Corrales Ulate 2011, 55). Estas declaraciones demuestran la composición social de clase media de la escena metal y su carácter juvenil, así como el carácter colaborativo de las agrupaciones que conforman la escena.

En cuanto a la dinámica de consumo musical metal, se constata que, en la década de 1980, el metal sigue al margen del paisaje sonoro, ya que solo existen dos comercios que distribuyen metal: Aucodisco y Eurometal (CarbaIlo 2017, 74 y 107). Por añadidura, el consumo musical evidencia una característica de clase. Paul Vega afirma: "era como elitista porque no era material que estaba al alcance de todos, algunos teníamos la suerte que teníamos amigos con la capacidad de adquirir ese material" (Corrales Ulate 2011, 58). Por otra parte, Fernando Baltodano, quien formó parte de la escena, menciona una vía de consumo popular que consistía en:

Ir donde el compa para que se lo grabara del LP al cassette [...] y de ese cassette a otros compas, y el último cassette ya ni se oía. Pero ese factor de conseguir música, artesanal le llamo yo, me parece una manera de vivir la generación dentro de la música en general, pero dentro del metal en particular (Corrales Ulate 2011, 59-60).

Este proceso de consumo popular logró permear hacia sectores juveniles de clase trabajadora y, por consiguiente, que surgieran bandas en los barrios de la periferia urbana.

Más adelante, hacia finales de la década de 1980, se observa que el rock obtiene una popularidad inédita. En 1986 se produce un factor catalítico, el disco Rock en tu idioma de la disquera BMG Ariola, que logró crear un mercado latinoamericano (Garibaldo y Bahena 2015, 202-205). Así, entre 1987 y 1990, las bandas Soda Stereo, Enanitos Verdes, Alux Nahual, Miguel Mateos y 
Zas, y el roquero Charly García realizaron conciertos y giras promocionales en el país. Encima, en setiembre de 1988, se produjo el concierto de mayor relevancia para el rock en Costa Rica, “iDerechos humano ya!” (Díaz Arias $2018,157)$. Estos eventos impulsaron la escena rock hacia la masividad, puesto que llenaron estadios.

La escena del rock costarricense, con agrupaciones de gran popularidad como Café con Leche, igualmente, buscó desarrollar eventos masivos, en los cuales participaron agrupaciones de metal, como Acero o Aquelarre. Se evidencia que el 20 de febrero de 1988, en el Autocine de Sabanilla (San José), se realizó un concierto con grupos como Café con Leche, U-Manos, Igni Ferroque, Excalibur y Acero. Con respecto a esta actividad, José Capmany, músico de Café con Leche, declaró: "será el primero y único concierto de esta temporada y quizá desde hace muchos años no se realiza uno de tal magnitud" (La Nación 1988a).

Sin embargo, sí se hizo otro concierto. A finales del mes de febrero, se llevó a cabo un recital de rock y metal en la Plaza de Toros de Zapote; el evento fue promovido por el Ministerio de Cultura. Luis Fernando Mata, periodista de La Nación, aclaró que la organización fue un fracaso y no permitió que la plaza estuviera llena, aunque "en lo musical fue un éxito, magnifico sonido y sorpresas, entre ellas la presencia de Solón Sirias como visitante y aficionado al 'Heavy Metal', al 'Pop Metal' y demás clasificaciones del género 'rockero'" (Mata 1988). La mención de Sirias, renombrado músico y líder de la agrupación Tinajas Brass, es importante porque permite constatar que el rock rompió el encercado de la moda juvenil y fue aceptado por el canon costarricense de música popular.

En este periodo, el metal formó parte de las actividades del rock, particularmente, lo que se llegaría a denominar rock en español (género que, entre los años finales de la década de 1980 y los primeros años de la década de 1990, formó su propia escena). Por su parte, el metal que, de igual manera, formaría su escena en estos años, se benefició de la popularidad y aceptación del rock en español para fortalecer sus actividades musicales. Inclusive, las agrupaciones de metal Armagedón y Distorsión grabaron canciones con el sello INDICA, las cuales fueron publicadas en 1988, en el disco Todo el rock, el cual reunió las mejores producciones del rock costarricense (La Nación 1988b).

\section{Cráneo Metal: reconfiguración de la escena metal}

Los límites entre la escena rock y la metal durante la década de 1980 no estaban definidos, y es hasta los últimos años de esa década y los primeros de 1990 cuando la escena metal desarrolló una dinámica particular, la cual conllevó al pánico moral de 1992 que impidió el fortalecimiento del metal hasta mediados de la década de 1990. Empero, ¿cómo se desarrolló la escena metal en este periodo? Este último apartado da respuesta a tal problemática. Por consiguiente, el objetivo planteado es analizar el proceso de consolida- 
ción de la escena metal. De acuerdo con este motivo, esta sección se organiza de la siguiente forma: primero, se observan las expresiones musicales metal; segundo, se examina la formación Cráneo Metal ${ }^{3}$, y, tercero, se identi- 3 . Cráneo Metal es en la fica el rechazo social que genera esta rama del rock.

actualidad una empresa promotora de eventos heavy metal que busca

En agosto de 1986, la banda La silla eléctrica realizó dos interpretaciones de un "Concierto de rock barato" con el fin de rememorar sus mejores años (1975-1980). Para ello, tocaron covers de la banda de rock psicodélico y heavy metal estadounidense Blue Öyster Cult. Asimismo, es de interés resaltar que en el evento se vendieron discos con los sencillos "Sex" y "The last time" que grabaron en 1985 (La Nación 1986). En ese mismo mes, esta agrupación hizo un concierto, en el Centro Comercial de Guadalupe que se transmitió en directo por televisión y radio (Antillón 1986). Lo anterior evidencia que el metal y el rock pesado contaban con espacios mediáticos y de posibilidades de promocionar sus expresiones musicales.

La música y las prácticas musicales metal fueron divulgadas paulatinamente. El 22 de agosto de 1987, el periodista de La Nación, Luis Fernando Mata, publicó una columna sobre el metal y sus estilos. Para ello recibió asesoría de Mariano Matamoros, guitarrista de Aquelarre, y Francisco Pujol, baterista de Acero, entre otros. Mata escribe sobre cuatro tendencias de metal: 1) el Heavenly, creada para alabar a Dios; 2) el Heavy, que tiene sus raíces en grandes músicos como Jimmy Hendrix, y habla de amor, sexo, violencia y drogas; 3 ) el Speed, que se basa en el virtuosismo de los guitarristas, bajistas y bateristas; y 4) el Black, cuyo director y profesor es el "mismísimo pisuicas". Asimismo, el crítico de La Nación reprueba esta música al declarar que los aficionados al metal "buscan la controversia, juegan de 'raros' y por desgracia, en nuestro país no faltan seguidores de estos 'músicos', cuyo arte deja mucho que desear".

A finales de la década de 1980, San Pedro de Montes de Oca (San José) se afirmó como un centro de música rock, ya que diversos bares (Barrock, Baleares, entre otros) sonaban la música y eran escenarios para las agrupaciones. No obstante, el bar Sand -antiguo Terra Nova- se convirtió en el centro de la escena metal. Paul Vega, al respecto, comenta:

Al final el bar fue tomado por asalto no sé en qué momento ya bajo el nombre de Sand, alrededor de 1987, [...] tiempo después al tipo no le quedó otra que aceptarlo porque la gente no dejaba de ir y no le dejaban de pedir que le pusiera metal, eso ya para el año 88 u 89 más o menos (Corrales Ulate 2011, 57).

Los conciertos, por su parte, si bien se afirma que se desarrollaban a escondidas y fuera del Valle Central (Mora 2011, IX), también se efectuaron en espacios urbanos: Armagedón realizó un concierto en el Teatro Eugene O’Neill; 
Acero y Aquelarre, en la Casa del Artista. Sobre este último, Paul Vega señala:

En la Casa del Artista, les prestaron para que tocaran Acero y Aquelarre, [...], todos llegábamos en grupo, nos aglomerábamos al frente de la Tarima y no parábamos de saltar y mover la cabeza, porque no había mosh, no podía decirse mosh porque en aquel momento no se le decía mosh, no tenía nombre (Corrales Ulate 2011, 58).

Las presentaciones metal continuaron su desarrollo. El 23 de setiembre de 1989, Luis Fernando Mata reporta para La Nación, en el artículo titulado "Rock en Beneficio del animal abandonado", que las bandas Argos, Mantra, Asepsia y Massacre se presentaron de forma gratuita en una actividad en beneficio del animal abandonado. Durante el concierto se vendieron camisetas y discos, probablemente de metal. Esta actividad benéfica no concuerda con la percepción negativa que se construyó alrededor del metal, como se verá en este apartado. Luego, el 20 de enero de 1990, se realiza un concierto en el cine de Cartago con las bandas Mantra, Asepsia y Acero (Mata 1990).

Estas expresiones musicales fueron vistas como una propuesta alternativa musical para la juventud. Roberto Pana, baterista de Mantra, declara: "aquí está pegado mucho el pop-rock, es algo muy común y popular porque a una mayoría le gusta lo tradicional, pero creo que debemos ofrecer algo distinto a la juventud" (Mata 1990). Asimismo, Pana agrega: "Nosotros jamás podemos llamarnos negativos, ni satánicos, ofrecemos a la gente otra alternativa, con una música de ritmo fuerte, original, pero con mensajes muy positivos y que se refieran a problemáticas sociales". Lo anterior evidencia la imagen negativa que se asocia con el metal, así como el esfuerzo de la escena por presentar el metal como una alternativa cultural legítima y pertinente al paisaje social costarricense. Así, la imagen negativa la retrata el baterista cuando, el 22 de diciembre de 1990, tocaron en Ciruelas de Alajuela (Alvarado 1990) y fueron culpados del terremoto que ocurrió ese mismo día (Carballo 2017, 108).

La autonomía de la escena metal seguía creciendo, y uno de los mayores esfuerzos por lograrlo fueron los festivales Cráneo Metal. La motivación por promocionar nuevas sonoridades metal llevó a José Pablo Vargas, estudiante universitario, a organizar en 1989 el primer festival. La primera edición se realizó, el 19 de agosto, en el Gimnasio Municipal de Desamparados. La asistencia al festival, 300 personas, concuerda con las declaraciones de Paul Vega sobre los y las participantes (y el carácter urbano) de la escena metal:

Era un grupo muy grande, yo podía contar en aquellos momentos para la época entre 300 a 500 personas que asistíamos regularmente a los conciertos de metal, ...siempre éramos los mismos, nosotros que éramos de Barrio Luján, los de Barrio Córdoba, la gente de Tibás, la gente de Moravia, ...éra- 
mos un grupo relativamente estable, fiel y por otro lado todos nos conocíamos y era poca la gente que no habíamos visto en esos conciertos porque éramos pocos (Corrales Ulate 2011, 56). En cuanto a la música, la biografía de Cráneo Metal afirma que:

El objetivo principal del evento fue poner en escena a dos bandas de géneros no tradicionales para la época, Massacre y Sepulcro. La primera con un Speed más agresivo y la segunda era una banda de Black Metal, de las primeras que tocaron tarimas en Costa Rica (Cráneo Metal 2016).

Lo anterior permite constatar la influencia de la producción noruega en la escena costarricense (Fuentes Belgrave 2004, 58), lo cual inserta a Costa Rica dentro de la dinámica global del metal, que es liderada por las agrupaciones: Mayhem, Darkthrone, Inmortal y Burzum (Castañeda 2005, 35). Asimismo, la producción noruega facilita la apropiación de simbología anticristiana y mitológica por parte de bandas locales. Estas declaraciones concuerdan con lo mencionado por Roberto Pana sobre lo "tradicional" y el autoposicionamiento del metal como una música alternativa y, por lo tanto, legítima.

A pesar de que el segundo festival fue cancelado, en estos años, Cráneo Metal "se consolida ya como una productora de eventos líder en la escena nacional y nuestros conciertos son reconocidos por los fans de la música quienes esperan con ansias el evento año tras año" (Cráneo Metal 2016). Por otro lado, se evidencia que la música metal, durante este periodo, se especializa en categorías que concuerdan con las expuestas por Luis Fernando Mata; en la biografía web de Cráneo Metal señala:

Además de la tradicional banda Mantra, se incluye a Karma, una banda que por primera vez en la escena incluye los teclados en su alineación. Viuda Negra, banda de músicos muy experimentados en el país quienes tocan básicamente un Heavy Metal... En este evento se adiciona también a Acepsia, banda de Speed Metal con temas cristianos que ya inician su incorporación en la escena y por último Sentence, que sería la banda más esperada en este evento, con un Death Metal ya muy bien definido y dos guitarristas que llegarían a marcar una pauta en el Metal de nuestro país (Cráneo Metal 2016). 
Para 1992, en la edición suspendida que causó el pánico moral, se iban a presentar las bandas: "Sentence, además de Massacre, Féretro y el debut Grindcore de Psy-War y de la banda Noise Morbid Symphony" (Cráneo Metal 2016). Massacre y Viuda negra son originarios de los barrios del sur de la capital (Corrales Ulate 2011, 57): un área urbana con un amplio sector de población trabajadora. Esto demuestra que la escena metal es más amplia que durante la década de 1980. Además, se evidencia que más locales distribuyen música metal, puesto que el afiche del concierto menciona tres comercios: Jungla del Disco, Fama Music y Enigma Records (Villalobos 1992); también indica que se harían rifas cortesía de Metamorfosis, probablemente otro establecimiento que distribuye material metal.

El último aspecto de esta sección trata sobre el rechazo social que padece la escena metal y que, durante el pánico moral de 1992, la convierte en objeto de control por parte de las autoridades estatales. En 1984, Carlos Rivera publica un artículo en La Nación que advierte sobre el rock -también agrupa el punk y el heavy metal-y su influencia en el consumo de drogas y el satanismo en los jóvenes, en particular al analizar la música de Black Sabbath. No obstante, Rivera advierte:

en Costa Rica, no ha encontrado muchos adeptos y más bien constituye una moda más que no pasa de unos cuantos mechones decolorados, plumas de ave en una oreja a modo de pendiente y los característicos y muy ceñidos 'jeans' (Rivera 1984).

La relación entre el rock y el metal con los cultos satánicos se expresa en febrero de 1986, cuando el Eco Católico reproduce un artículo publicado en la revista Reino de Cristo de España. En esta ocasión, se enumeran las canciones de rock y metal, y se "revela" su mensaje satánico, descubierto por la inversión de los discos o en las ilustraciones de los vinilos (Sánchez 1986). Por añadidura, el párroco de San Pablo de Heredia, Edwin Sánchez, quien reprodujo el artículo mencionado, en "La música del diablo", publicada el 25 de mayo de 1986 por el Eco Católico, agrega que:

Desgraciadamente existe la música que ya no es creación o contribución a la creación de la grandeza de las cosas de Dios, sino destrucción, descentralización, dispersión, etc. de la cual debemos dudar y desconfiar. Este tipo de música (la diabólica) ya no es una forma de liberación de la creatividad constitutiva del hombre, sino una 
forma de manipulación y atenta contra las cualidades hu-

manas.

En el año 1989, la localidad de Heredia se alarmó por el primer festival Cráneo Metal; el gobernador de Heredia, Luis Martínez Ramírez, al sostener el afiche que anuncia el festival, asegura que existe una vigilancia estricta para impedir la propagación de dibujos satánicos (Zamora 1989). Estas declaraciones se debieron a que el sacerdote de la Parroquia de la Inmaculada Concepción de Heredia, Jorge Calvo, denunció la conformación de bandas juveniles dedicadas al satanismo, las cuales tendrían no menos de 100 integrantes (Zamora 1989). Con todo, el Organismo de Investigación Judicial (OIJ) no ha recibido advertencias ni ha encontrado pruebas; empero, Calvo aseguraba: "tenemos informes de que en sus rituales consumen drogas fuertes como cocaína, licor, matan animales y toman su sangre, realizan orgías, escuchan música que los pone violentos. Se habla de dos jóvenes que están embarazadas y sacrificarán a sus hijos" (Zamora 1989).

Bajo una misma línea, Enrique Tovar, quien 10 años antes escribió sobre el bar Génesis, publica desde Nueva York una reseña del reporte de la Asociación Médica de los Estados Unidos (AMA), en el que se advierte sobre el peligro de la música metal. Tovar — que no se apropia de la preocupación estadounidense, pero tampoco la critica- reproduce el discurso de la AMA que sugiere que:

Las imágenes violentas, aún sádicas y líricas del rock duro metal podría ser una respuesta de la edad de la cultura del rock [...] pero hay una evidencia real de que los adolescentes involucrados en la subcultura del rock duro corren mayores riesgos del abuso de droga o aún la participación de actividades satánicas (Tovar 1989).

En suma, esto y lo mencionado en los párrafos anteriores demuestra la preocupación que existía debido a las actividades de la escena metal. En consecuencia, un mayor número de estas actividades y la ansiedad por controlarlas desencadenó un pánico moral que pondría fin a una época del rock y el metal en Costa Rica. Este pánico fue ocasionado el 31 de mayo de 1992, luego de que el cuarto festival Cráneo Metal fuera suspendido por la policía; circunstancia que escaló hacia una preocupación social, la cual se expresó en acciones policiales y en el debate público (Hernández Parra 2016). En consecuencia, se demonizó a los y las aficionadas al metal y sus actividades, condenadas. No obstante, después de este acontecimiento, diversas prácticas de la música popular lograron desplegarse y se constituyeron en movimientos juveniles subculturales como el goth, el punk (Fuentes Belgrave 
2004) y el ska (Álvarez y Obando 2015), los cuales, hacia finales del siglo XX, conforman nuevas cartografías culturales (Zúñiga 2006).

\section{Conclusión}

El metal como práctica musical que motiva la interacción social, durante las décadas de 1970 y 1980, conformó una escena que creció junto a la vertiginosa popularidad del rock y su vertiente en español; y para fines de la década de 1980, junto con el esfuerzo Cráneo Metal, logró mayor autonomía. No obstante, en 1992 se paralizó. Esta situación llevó a que se reconfigurara la escena metal, la cual, en años posteriores, tuvo un mayor dinamismo y popularidad, incluso, en los años que siguieron a 1992, las diversas escenas musicales tributarias del rock (punk, ska, metal, goth, entre otras) y sus identidades subculturales se fortalecieron.

El párrafo anterior resume el argumento de este artículo, el cual examinó la construcción de la escena musical metal en Costa Rica. En consecuencia, en este trabajo se desarrolló adecuadamente el objetivo propuesto: analizar la construcción de la escena musical metal en Costa Rica. Con el fin de solventar este objetivo, la investigación planteó como herramienta teórica la escena musical, que se concibe como una relación social generada por la práctica musical.

Por consiguiente, a lo largo del texto se logró: 1) determinar las primeras agrupaciones e influencias del rock que permitieron el surgimiento de sonoridades metal; 2) exponer el traslado de los espacios de interacción musical, en donde adquirió predominancia el bar como espacio de consumo especializado, y 3) detectar la nueva dinámica de la actividad musical en la década de 1980 motivada por el rock, de la cual el metal fue parte, pero se estableció como un discurso musical diferenciado. Con todo, la música metal fue tomando protagonismo dentro del paisaje musical popular urbano costarricense; visibilidad de la práctica musical que se fue construyendo desde la cultura hegemónica como una actividad amenazante.

En suma, a lo largo del trabajo, se ha constatado cómo las prácticas musicales rock fueron el motor que potenció el surgimiento y la especialización de la escena metal, la cual compartió escenarios y producciones discográficas con el rock en la década de 1980. Asimismo, se comprobó que la escena metal se diversificó y añadió sonoridades y prácticas (definidas como alternativas legítimas) que llevaron a una creciente estigmatización social que, paradójicamente, consolidaron su identidad.

\section{Bibliografía}

Acuña Zamora, Gilbert, Grace Aguilar, Alonso Brenes, Elizabeth Chinchilla, Jeanette García y Marta Morera. 1996. "Exhibiciones cinematográficas 
en Costa Rica (1897-1950)". Seminario de graduación de Licenciatura en Historia: Universidad de Costa Rica.

Alvarado, Álvaro. 1990. "En frecuencia”. La Nación, 22 de diciembre: 16 Viva.

Álvarez López, Jessica y Fernando Obando Reyes. 2015. "Juventud y chivos de Ska: una forma de gestión cultural alternativa". Tesis de Licenciatura en Antropología Social: Universidad de Costa Rica.

Antillón, Luis Guillermo. 1986. "Grupo se disculpa”. La Nación, 26 de agosto de 1986: 16A.

Bennett, Andy. 2004. Cultures of popular music. Buckingham, Reino Unido: Open University Press.

Bennett, Andy. 2004. "Consolidating the music scenes perspective". Poetics 32: 223-234.

Brenes de Charpentier, Lidiette. 1982. "La moda punk, violencia en el vestir y en otras cosas". La Nación, 1 de agosto: 2C.

Carballo, Priscilla. 2017. Por las calles del rock. Aproximaciones al desarrollo del rock en Costa Rica. 1970-1990. San José, Costa Rica: Editorial Arlekín.

Castañeda, Mario. 2005. "Bajo el resplandor del metal: un intento por explicar la historia del Heavy Metal”. En Culturas juveniles, teoría, historia y casos, compilado por Mario Zúñiga Núñez. 21-49. San José, Costa Rica: Cuadernos de Ciencias Sociales 136.

Corrales Ulate, Rafael. 2011. "Camisetas negras, una expresión alternativa: estudio sobre el movimiento metalero urbano en Costa Rica". Tesis de Licenciatura en Antropología Social: Universidad de Costa Rica.

Cousinet, Graciela, Marcelo Padilla, Víctor Etepa y Marcelo de Luca. 2009. Extramuros. La historia del movimiento rock mendocina (1958-1998). Mendoza, Argentina: EDIUNC.

Cráneo Metal. 2016. "Biografía" acceso el 26 febrero 2016. http://www.craneometal.com/contenido/biograf\%C3\%ADa

Cuevas Molina, Rafael. 2013. "Identidad y cultura en Costa Rica a inicios del siglo XXI". En Costa Rica en los inicios del siglo XXI, coordinado por Adalberto Santana, 123-137. Heredia, Costa Rica: EUNA.

Díaz Arias, David. 2018. "Hijos de la crisis. La juventud costarricense de la década perdida". En La inolvidable edad. Jóvenes en la Costa Rica del siglo XX, editado por Iván Molina y David Díaz, 135-160. Heredia, Costa Rica: EUNA.

Fallas, Héctor. 1980. "Larga vida del rock". La Nación, 3 de octubre: 14C.

Feixa, Carles. 1998. De jóvenes, bandas y tribus. Antropología de la juventud. Barcelona: Ariel. 
Fuentes Belgrave, Laura. 2004. "La construcción simbólica del "underground" Goth y Punk en la juventud del Área Urbana costarricense". Tesis de Licenciatura en Ciencias de la Comunicación Colectiva: Universidad de Costa Rica.

Garibaldo Valdés, Ramón y Mario Bahena Urióstegui. 2015. “El ruido y la nación: cómo el rock iberoamericano redefinió el sentido de comunidad en Latinoamérica". Diálogos Revista Electrónica de Historia, 16, N. 1: 191-214.

Hernández Parra, Sergio Isaac. 2016. “Jóvenes, 'rock satánico' y el pánico moral de 1992 en Costa Rica”. Tesis de Licenciatura en Historia: Universidad de Costa Rica.

Kauskopf, Dina y Ana Lucía Gutiérrez. 1990. Características sociodemográficas de la Juventud de Costa Rica, San José, Costa Rica: Universidad de Costa Rica, Instituto de Investigaciones Sociales.

La Nación. 1982, setiembre 4. "Festival de 'rock' celebran en el Carpa”. La Nación, 5B.

La Nación. 1986, agosto 1. "Conectan de nuevo a La silla eléctrica", La Nación, 2C.

La Nación. 1988(a), febrero 19. "Músicos se unirán mañana en concierto”. La Nación, 18 Viva.

La Nación. 1988(b), enero 14. “Disco une al 'rock' nacional”, La Nación, 18 Viva.

Lancina, Josep Lluís. 2017. “En La Roca, el hardcore es cultura'. Las prácticas DIY y la construcción de una identidad local". Cuadernos de Arte e Antropología, 5, N. ${ }^{\circ}$ 1:37-52.

Marín Hernández, Juan José. 2009. Melodías de perversión y subversión. La música popular en Costa Rica, 1932-1960. San José, Costa Rica: Editorial librería Alma Mater.

Mata, Luis Fernando. 1987. "Vida Rosa”, La Nación, 22 de agosto: 12 Viva.

Mata, Luis Fernando. 1988. "Vida Rosa”, La Nación, 3 de marzo: 12 Viva.

Mata, Luis Fernando. 1989. “Woodstock veinte años después”. La Nación, 14 de agosto: Portada Viva.

Mata, Luis Fernando. 1989. "Rock en beneficio del animal abandonado", La Nación, 20 setiembre: 12 Viva

Mata, Luis Fernando. 1989. "Rock a la española". 11 de octubre: Portada Viva.

Mata, Luis Fernando. 1990. 'Heavy Metal' en Cartago”, La Nación, 20 de enero: 12 Viva. 
Mendívil, Julio y Christian Spencer Espinosa. 2016. "Epilogue: reconsidering music scenes from a Latin America perspective". En Made in LAtin America. Studies inpopular music, editado por Julio Mendívil, y Chistian Spencer Espinosa, 160- 164. Nueva York: Routledge.

Mendívil, Julio y Christian Spencer Espinosa. 2016. "Introduction: debating genre, class, and identity: popular music and music scenes from the Latin America world." En Made in LAtin America. Studies in popular music, editado por Julio Mendívil, y Christian Spencer Espinosa, 1-22. Nueva York: Routledge, 2016.

Minsky, Larissa.1991. "Rock, el ritmo que cambió al mundo". La Nación, 29 de diciembre:6-7 y 10 Dominical.

Molina Jiménez, Iván. 2010. Costarricense por dicha. Identidad nacional y cambio cultural en Costa Rica durante los siglos XIX y XX. San José, Costa Rica: Editorial UCR.

Mondol, Mijaíl. 2015. Tango, arrabal y modernidad en Costa Rica. San José, Costa Rica: Editorial Costa Rica.

Montes, Tony. 1980. "DIDECA + setiembre= rock". Eco Católico, 21 de setiembre: 8 Betania.

Montes, Tony. 1982. “Rotundo triunfo de 'Chacal'”. Eco Católico, 14 de marzo: 8 Campesino.

Mora, Víctor. 2011. Enciclopedia del Metal Costarricense (y otras influencias), San José, Costa Rica: Subterranean Gremio de Escritores.

Passerini, Luisa. 1996. "La juventud, metáfora del cambio social: dos debates sobre los jóvenes en la Italia fascista y en los EE. UU. durante los años cincuenta". en Historia de los jóvenes II. La edad contemporánea, coordinado por Giovanni Levi y Jean Claude Schmitt. 381-453. Madrid: Santillana.

Rivera, Carlos. 1984. “¿Qué nos dice la música rock?”. La Nación, 4 de agosto: $2 \mathrm{~B}$.

Sánchez, Edwin. 1986. "La música del diablo”. Eco Católico, 23 de febrero: 5.

Sánchez, Edwin. 1986. "La música del diablo”. Eco Católico, 25 de mayo: 13.

Sans, Juan Francisco. 2016. "Ninteenth century spanish american salón as a traslocal music scene". En Made in LAtin America. Studies in popular music, editado por Julio Mendívil, y Christian Spencer Espinosa, 37-46. Nueva York: Routledge.

Semanario Universidad. 1990, noviembre 2. "Infórmese con música rock y popular". Semanario Universidad, 2.

Sequeira, Paula. 2020. "Los hippies como metáfora de la ambigüedad o del por qué se los responsabiliza por el surgimiento de la 'ideología de 
género' en Costa Rica". Cuadernos Inter.c.a.mbio sobre Centroamérica y el Caribe 17 (2): 1-29. doi:https://doi.org/10.15517/c.a..v17i2.43520

Torres Rivas, Edelberto, 1987. "La cuestión juvenil en Costa Rica, reflexiones preliminares". Cuadernos de Ciencias Sociales, no. 9.

Tovar, Enrique. 1979. “Génesis: primer centro de cultura 'rock”". La Nación, 2 de marzo: Portada sección B.

Tovar, Enrique. 1989. "Música rock podría llevar jóvenes a ritos satánicos". Semanario Universidad, 20 de octubre: 6.

Villalobos, Lorena. 1992. “El metal de la guitarra”. La Nación, 3 de junio: $10 \mathrm{~A}$.

Zamora Ocampo, Tomas. 1989. "Sacerdote denuncia acciones satánicas". La Nación, 8 de setiembre: 8 A.

Zúñiga Núñez, Mario. 2006. Cartografía de los mundos posibles: el rock y reggae costarricense según sus metáforas. Heredia, Costa Rica: Editorial de la Universidad Nacional. 